\title{
Article
}

\section{Comparison of Change Estimation between Four Ground-Survey Methods for Use in a Continuous Forest Inventory System}

\author{
Nelson Y. Nakajima*1, Shigejiro Yoshida*2 and Masaaki Imanaga*3
}

\begin{abstract}
In this study we compare the accuracy with which four ground-survey techniques estimate change. The methods compared are; point sampling (PS), line sampling (LS), circular plot (CP), and concentric circular plot $(\mathrm{CCP})$, which can all be used as permanent samples in a continuous forest inventory system. Data were collected on two occasions from a sugi (Cryptomeria japonica D. DON) stand in the Takakuma Experimental Forest, Kagoshima Prefecture, Japan. For the PS and LS methods a basal area factor of 4 was used. For the LS method, the line length was $10 \mathrm{~m}$, and the stems on both sides of the line were selected. For the CP method, the radius was $6 \mathrm{~m}$, corresponding to $0.011 \mathrm{ha}$; and for the $\mathrm{CCP}$ method, the radii were 5 and $10 \mathrm{~m}$, corresponding to 0.008 and 0.031 ha respectively. Twelve samples were systematically sampled and the process repeated 10 times for each method. The CP method was the most accurate for estimating the change in the number of stems per hectare, but there were no significant differences between the four methods for estimating basal area or volume.

Keyword: point sampling (PS), line sampling (LS), circular plot (CP), concentric circular plot (CCP), change estimation
\end{abstract}

\section{INTRODUCTION}

Change, or growth, may be estimated from differences between independent plots measured on two occasions, from remeasured plots, or from a combination of both (SCOTT and KoHL 1994).

According to HuScH et al. (1982) successive sampling in forest inventory has three objectives: to estimate the quantities and characteristics of the forest at the first inventory; to estimate the quantities and characteristics of the forest at the second inventory; and to estimate changes

*1 United Graduated School of Agricultural Sciences, Kagoshima University, 1-21-24 Korimoto, Kagoshima 890 Japan

*2 Faculty of Agriculture, Kyushu University, 6-10-1 Hakozaki, Higashi-ku, Fukuoka 812 Japan

*3 Faculty of Agriculture, Shizuoka University, 836 Ohya, Shizuoka 422 Japan in the forest during the intervening period. Sample units measured on the first occasion and remeasured on the second and all succeeding inventories are referred to as permanent sample plots and are the basis of continuous forest inventory (CFI). Permanent sample plots may be selected randomly or systematically to represent the entire forest population.

SCHMID-HAAS et al. (1993) recommend that permanent sample plots should be unmarked to ensure that management activities in the sample plots are as uniform as those applied to the entire population. But one of the difficulties of continuous forest inventory has been the exact relocation of the plots in subsequent measurements. Other disadvantages of permanent plots are that plots in distinct strata or regions may be lost, samples may not be representative over time, or the number of samples can become too low for some units of reference (KoHL et al 1995). WEST (1995) recommends that, because variability in forests is generally high, it is important to maximize the sampling intensity. VANCLAY et al. (1995) recommend that 
permanent sample plots should include a wide range of sites (all climatic zones and soil types) and stand conditions to ensure valid inferences.

Inventory on successive occasions is the basis of forest management decisions, silvicultural guidelines, yield tables, yield prediction, health monitoring, long-term productivity monitoring and analysis of the socio-economic influences of forests (VANCLAY et al. 1995; ADLARD 1995).

In forestry, the term "growth" is often used synonymously with "change", despite the former's implication of positive change. Among forest scientists and practitioners there is long-standing disagreement about the merits of growth estimation from sample designs which use fixed-area plots versus those which use horizontal points or variable radius plots (GREGOIRE 1993).

BICKFORD et al. (1963), cited by KoHL et al. (1995), reported that despite the use of sampling with partial replacement (SPR) since the 1960 s, there are only a few instances when SPR has been used on more than two occasions. The tendency has been to abandon SPR and move back to CFI or to other techniques such as updating techniques based on growth projection models (HAHN and Hansen 1983, cited by KoHl et al. 1995). ScotT (1986), cited by KOHL et al. (1995) recommends simplification by returning to CFI particularly now that change is at least as important as current values. The CFI design is less efficient, but due to its simplicity, is more appropriate for most practical applications and continuous surveys over more than two occasions (KoHL et al. 1995).

The objective of this study was to compare the accuracy with which four ground-survey methods estimate change. Each method can be used for permanent samples for CFI, and are; point sampling (PS), line sampling (LS), circular plot $(\mathrm{CP})$, and concentric circular plot $(\mathrm{CCP})$.

\section{STUDY AREA AND METHODS}

Study area

The study was conducted in the Takakuma Experimental Forest, situated within the jurisdiction of Tarumizu City in Kagoshima Prefecture, on an area of 2.8ha. The terrain is broken and the gradient ranges from 5 to 50 degrees. In 1926, a sugi (Cryptomeria japonica D. DoN) forest was established with an initial spacing of about 2 $\mathrm{m} \times 2 \mathrm{~m}$. In 1981, when the stand was 55 years old, the first measurement of the entire study area was performed, and the second was conducted in 1991. The homogeneous even -aged stand, then 65 years old, had never been thinned.
Forest survey, sampling process and ground-survey methods

For the complete survey of the forest, the entire study area was divided into plots of $10 \mathrm{~m} \times 10 \mathrm{~m}$, and a stake was driven on one corner of each plot. These stakes were used as reference points in the measurement of individual trees with diameters at breast height of $4 \mathrm{~cm}$ or more $(\mathrm{dbh} 4 \mathrm{~cm})$. The data collected were tree location coordinates, dbh, and height (YoshidA 1984).

Sampling of the forest was simulated using the data collected from the complete enumeration of the forest. The maximum number of plots allowed for the entire area was 12 , so 12 samples were systematically selected for each survey method. Sampling was conducted 10 times for each method. To avoid bias, a minimum distance between the stand boundary and the sample-plots was observed. The data from the complete forest survey (tree location coordinates, dbhs and heights) was entered into a computer and a BASIC program written to select the sample trees of each method was used.

PS and LS are plotless sampling methods without a defined area, the CP method is a fixed-radius plot with a defined area, and the CCP method a combination of circles with two different radii. To compare the plots fairly, the plot sizes of the four methods were adjusted so that each plot had a uniform number of stems, using the PS method as a reference. The average number of stems in PS method was first counted and the other three methods were then adjusted to have the same number of stems as the PS method.

For the PS and LS methods, a basal area factor of 4 was chosen; in the LS method the line length was $10 \mathrm{~m}$, and the sample trees on both sides of the line were selected. For the $\mathrm{CP}$ method the radius was $6 \mathrm{~m}$, corresponding to 0.011 ha, and all trees with $\mathrm{dbh} 4 \mathrm{~cm}$ and whose center was located inside the plot were selected. For the CCP method, the radii of the smaller and larger circles were 5 and $10 \mathrm{~m}$, corresponding to 0.008 and 0.031 ha, respectively. The criteria for the selection of borderline trees was the same as for the $\mathrm{CP}$ method. In the smaller circle, all trees between $4 \leqq \mathrm{dbh}<30 \mathrm{~cm}$ were selected, and in the larger circle all trees with $\mathrm{dbh} \geqq 30 \mathrm{~cm}$ were selected. On both occasions (1981 and 1991) the same sample-plot characteristics (basal area factor, line length and radius) and sampling point locations for the four methods were used. For each of the four methods, the population was considered infinite, and the level of confidence was set at $95 \%$.

The authors have given the formulae for estimating current values and the statistical analyses of the four methods in an earlier paper (NAKAJIMA et al. 1995). 
Change estimation and statistical analysis formulae

The estimation of the current values, and statistical analyses at each inventory were conducted as in the case of two separate inventories. Differences between means at each inventory represent the changes in the forest. However, because the same sampling units are used on both occasions, the standard error of the difference is calculated as for paired plots (Husch et al. 1982). This calculation should take into account any removed trees on both occasions.

The change estimation and statistical analyses were conducted using the following formulae (PELLICO-NETTO and BRENA 1993):

$d_{m}=(y-x)$ (there was no thinning),

$s_{d}^{2}=\left[\left(s_{x}^{2}+s_{y}^{2}-2 s_{x y}\right)\right] / m$,

$s_{d}=\operatorname{sqr}\left(s_{d}^{2}\right)$, and

$s e=\left(t \times s_{d} / d_{m}\right) \times 100$

where:

$d_{m}=$ mean change or growth of the estimated variable

$y=$ mean of the estimated variable at the second occasion

$x=$ mean of the estimated variable at the first occa sion

$s_{d}{ }^{2}=$ variance of the change or growth

$s_{x}{ }^{2}=$ variance of the estimated variable at the first occasion

$s_{y}{ }^{2}=$ variance of the estimated variable at the second occasion

$s_{x y}=$ covariance between the first $(x)$ and second $(y)$ occasions

$m=$ number of samples measured at the first occasion and remeasured at the second occasion

$s_{d}=$ standard deviation

$s e=$ sampling error as percentage

$t$ = student table value $\left[\hbar_{0.05,22)}=2.07\right]$

Further details about the study area and methods can be found in NAKAJIMA et al. (1996).

\section{RESULTS AND DISCUSSION}

Stand parameters

The study area was $2.8 \mathrm{ha}$, and the number of trees surveyed at the first and second occasions were 3,433 and 3,037 trees respectively. Table 1 shows the stand parameters on both occasions and their change.

Details of the diameter distribution, statistical analyses, and the accuracy of the estimations for each survey method are presented in a former paper (NAKAJIMA et al. 1996) .

Comparison of the accuracy of the estimation of change between the four methods

On the first occasion the sample plot size of each method was adjusted to have, on average, the same number of stems (14 stems per sample). But, on the second occasion (10 years later), despite the use of the same sample plots, the mean number of trees sampled was different from the first occasion, because there were ingrowth trees. For the PS and CCP methods, the average number of stems per sample plot increased to 16 and 15 stems, respectively. HRADETZKY (1995) reports that in forest inventories using PS as permanent samples, the composition of samples from successive measurements change due to sample trees being selected with a probability proportional to basal area. For this reason, the variance of estimators of growth based on this type of data tends to be very high.

In the LS method, the number of stems measured on the second occasion stayed the same (14 stems). For the $\mathrm{CP}$ method, the number of stems per plot decreased to 12 stems. In this method, the sample-plot area is fixed and the growth of trees had no influence (i.e., there were no ingrowth trees), but the death of trees resulted in fewer stems being sampled on the second than on the first occasion.

Fig. 1 shows, for each of the four ground-survey methods, the estimated change values (left column) and respective sampling errors (right column), for the number of stems per hectare (stems/ha), basal area per hectare $\left(\mathrm{m}^{2} / \mathrm{ha}\right)$, and volume per hectare $\left(\mathrm{m}^{3} / \mathrm{ha}\right)$.

Table 1 Stand parameters on each occasion and their change

\begin{tabular}{lccc}
\hline Parameter & First occasion & Second occasion & Change \\
\hline Mean number of stems $/$ ha & 1,226 & 1,085 & 141 \\
Mean dbh $(\mathrm{cm})$ & 23.5 & 26.7 & 3.2 \\
Diameter range $(\mathrm{cm})$ & $4-68$ & $6-79$ & - \\
Mean total height $(\mathrm{m})$ & 13.1 & 15.8 & 2.7 \\
Mean basal area $\left(\mathrm{m}^{2} / \mathrm{ha}\right)$ & 58.8 & 66.5 & 7.7 \\
Mean volume $\left(\mathrm{m}^{3} / \mathrm{ha}\right)$ & 409.2 & 525.3 & 116.1 \\
\hline
\end{tabular}


a)

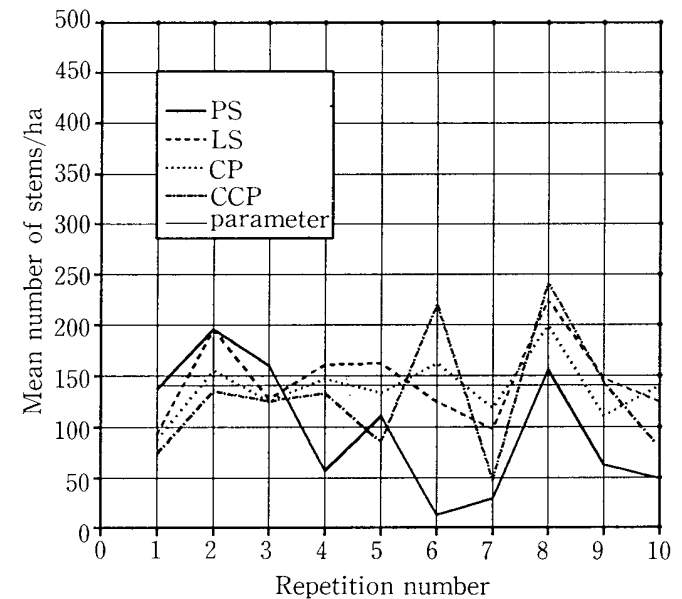

b)

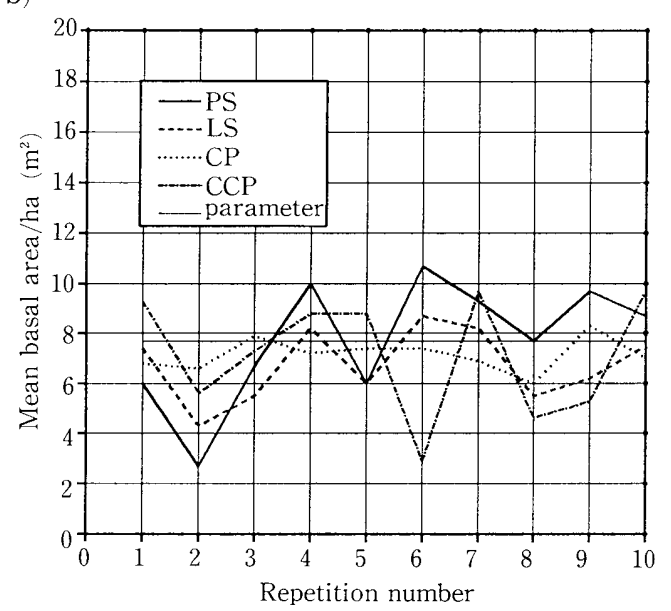

c)

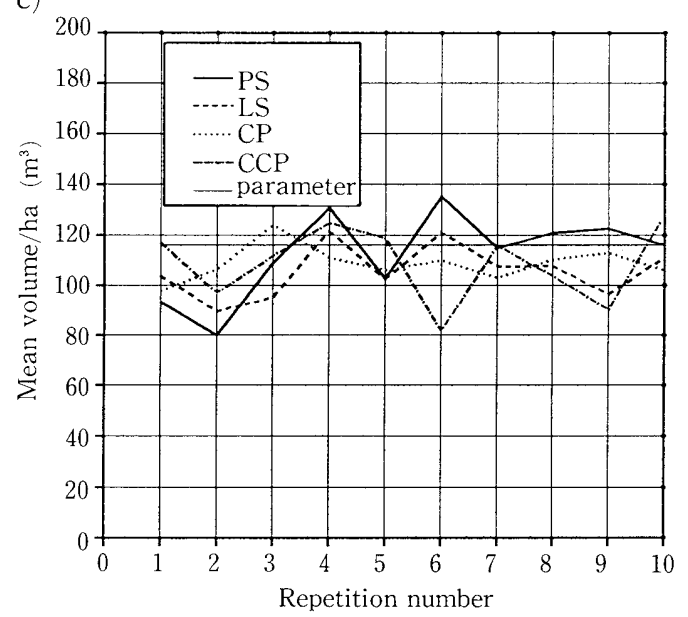

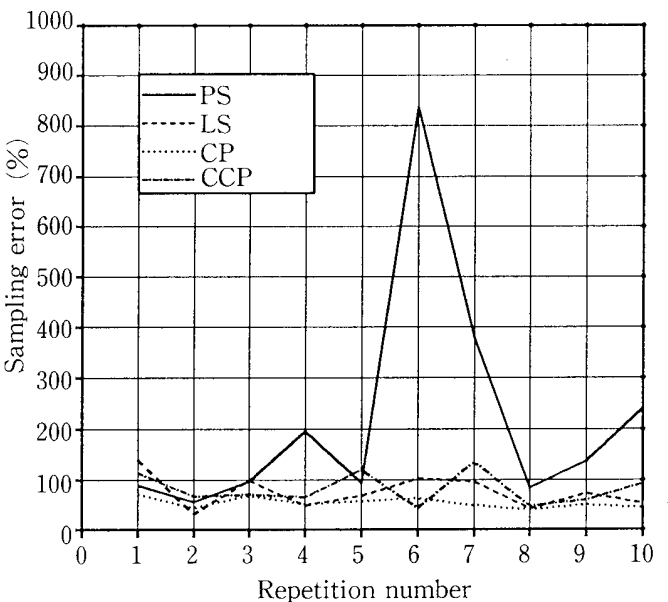
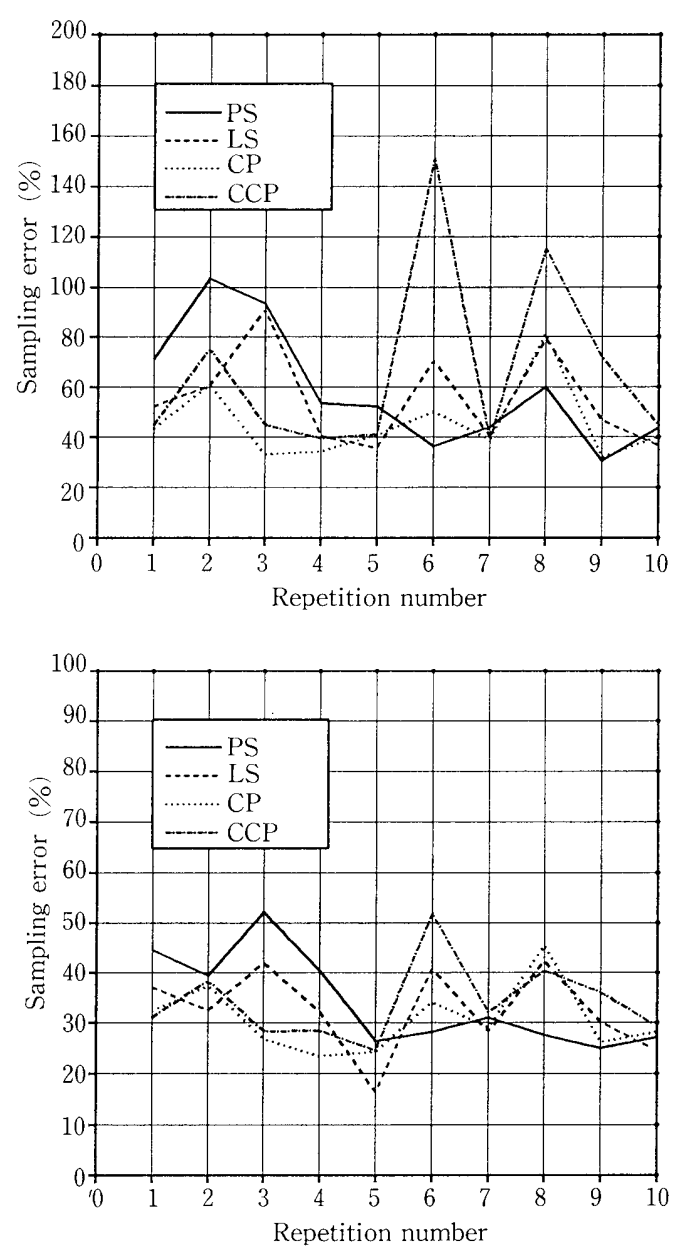

Fig. 1 Comparison of the estimated changes (left column) and sampling errors (right column) among the four ground-survey methods. a) number of stems/ha; b) basal area/ha; c) volume/ha. 
Over the 10 repetitions, the $\mathrm{CP}$ method gave the closest estimation of the change in each stand parameter the most number of times. The $\mathrm{CP}$ method also had the lowest average sampling error for each stand parameter, followed by the LS method. The sampling error for the change in the number of stems was lower for the $\mathrm{CP}$ method than the other three methods. However, for volume and basal area change there were no significant differences between the 4 methods, at a confidence level of $95 \%$ (test of hypothesis, $\mathrm{t}$-distribution). According to HradeTzKY (1995), the variance of the calculated growth is reduced in $\mathrm{CFI}$, because the covariance between the first and second occasion is positive and the degree of covariance is higher if the same trees are measured at both inventories, as in the CP method. LoETSCH et al. (1973) state that simple plots (e.g. CP) are superior to combined and Bitterlich plots (PS) for CFI, because in simple plots the same trees are remeasured at every mensuration. SCHMID-HAAS et al. (1993) recommend that after defining a plot size, it should stay the same as long as possible.

In the PS, LS and CCP methods, the plot size varies with tree size and they are therefore less appropriate than the CP method for CFI.

Tables 2 and 3 show the tests of comparisons between sampling errors of the four methods, and the means of the estimated change values from 10 repetitions, as well as the results of statistical analyses, respectively.
YANG and WANG (1987) report that permanent horizontal line sampling (LS) for forest growth estimation is problematic, because ingrowth trees which were originally out of the plot are suddenly included at the next measurement period even though there was little diameter growth. This can sometimes cause an abrupt change in the estimated volume per hectare, and YANG and WANG (1987) assert that this is caused by the estimation technique rather than actual growth. In this study, the LS method did not show an abrupt change in volume between measurements.

\section{CONCLUSIONS}

In prior papers we (NAKAJIMA et al. 1995, 1996) compared the accuracy of the same four ground-survey methods for the estimation of current values of two distinct experimental forests. We found that when estimating basal area and volume in a stand where the tree distribution was almost random (Shiragadake Experimental Forest), the PS method was the most accurate, followed by the CCP method (see NAKAJIMA et al. 1995). In a stand where the tree distribution was approximately a square lattice pattern (Takakuma Experimental Forest), the CCP method was the most accurate (see NAKAjIMA et al. 1996). For estimating the number of stems the $\mathrm{CP}$ method was the most accurate in both stands. However, we concluded that

Table 2 Comparisons between sampling errors of the four methods

\begin{tabular}{lcccccc}
\hline Variable & PS vs LS & PS vs CP & PS vs CCP & LS vs CP & LS vs CCP & CP vs CCP \\
\hline Number of stems & $2.00^{\text {ns }}$ & $2.24^{\text {ns }}$ & $1.79^{\text {ns }}$ & $2.72^{*}$ & $0.52^{\text {ns }}$ & $2.71^{*}$ \\
Basal area & $0.50^{\text {ns }}$ & $1.70^{\text {ns }}$ & $0.52^{\text {ns }}$ & $1.66^{\text {ns }}$ & $1.11^{\text {ns }}$ & $2.15^{\text {ns }}$ \\
Volume & $0.56^{\text {ns }}$ & $0.91^{\text {ns }}$ & $0.04^{\text {ns }}$ & $0.83^{\text {ns }}$ & $0.62^{\text {ns }}$ & $1.65^{\text {ns }}$ \\
\hline
\end{tabular}

$*$ : differences were significant at $t_{\text {cal }} \geqq t_{\text {tab }(9 ; 0.05)}=2.26$.

ns: no significant

Table 3 Estimated change and statistical analyses

\begin{tabular}{|c|c|c|c|c|}
\hline Statistical analyses & PS & LS & $\mathrm{CP}$ & $\mathrm{CCP}$ \\
\hline \multicolumn{5}{|c|}{ For number of stems $(\mathrm{N}=141$ stems $/$ ha $)$} \\
\hline Mean num. of stem/ha & 97 & 146 & 138 & 129 \\
\hline Standard deviation & 55.7 & 48.1 & 35.0 & 42.8 \\
\hline Sampling error & 220.8 & 75.6 & 53.9 & 81.6 \\
\hline \multicolumn{5}{|c|}{ For basal area $\left(\mathrm{G}=7.7 \mathrm{~m}^{2} / \mathrm{ha}\right)$} \\
\hline Mean basal area/ha $\left(\mathrm{m}^{2}\right)$ & 7.7 & 6.8 & 7.1 & 7.2 \\
\hline Standard deviation & 2.0 & 1.8 & 1.5 & 2.0 \\
\hline Sampling error & 58.9 & 55.4 & 45.5 & 66.8 \\
\hline \multicolumn{5}{|c|}{ For volume $\left(\mathrm{V}=116.1 \mathrm{~m}^{3} / \mathrm{ha}\right)$} \\
\hline Mean volume/ha $\left(\mathrm{m}^{3}\right)$ & 112.6 & 105.6 & 108.8 & 108.9 \\
\hline Standard deviation & 18.3 & 16.6 & 16.1 & 17.5 \\
\hline Sampling error & 34.2 & 32.6 & 30.7 & 34.1 \\
\hline
\end{tabular}


there were no marked differences between the sampling techniques in the accuracy of their estimates.

In this paper we compared the accuracy of the four ground-survey methods for estimating changes in the number of stems, basal area, and volume. Under the conditions of the study area, the CP method was the most accurate, especially for estimating the number of stems. However, for estimation of the change in volume or basal area, there were no significant differences between the sampling methods.

Based on the estimation of current values and change, we conclude that among the four ground-survey methods compared, there is no single method which is unanimously best for estimating both current values and change. Generally speaking, for estimating current values, there were no marked differences between the four methods, but for estimating change the $\mathrm{CP}$ method was the best. However, it is also desirable that the ground-survey method used to estimate current values and change is efficient. An efficient ground-survey method should not only be accurate, but should also be cost-effective and easy to apply, as this directly affects the amount of time spent in plot establishment and data surveys. Therefore, our next study will compare the amount of time spent in plot establishment and data surveys for each of the same four methods. We hope we will then be able to select the most appropriate ground-survey method for use in CFI for forest management.

\section{ACKNOWLEDGEMENTS}

The authors thank Prof. Dr. Masamichi Chyo (Kagoshima Univ. Forest), Prof. Dr. Koji Matsushita (Kyoto Univ.) and Miss Yoko NAKASHIMA for their valuable cooperation. We are also very grateful to Engineers Yuji YamanaKa, Hiroaki Kamizono, Kazuaki Seto, Motoi Uesugi, Mizuki KikunaGa, and Masaki Motomochi for collecting the data.

\section{LITERATURE CITED}

ADLARD, P.G., (1995): Myth and reality in growth estimation. For. Ecol. Manage. 71:171-176

Gregoire, T.G., (1993): Estimation of forest growth from successive surveys. For. Ecol. Manage. 56:267-278

Hradetzky, J., (1995): Concerning the precision of growth estimation using permanent horizontal point samples. For. Ecol. Manage. 71: 203-210

Husch, B., Miller, C.I. and BeERs, T.W., (1982) : Forest mensuration. (3 rd. Ed.). John Wiley \& Sons, New York, 402pp

Kohl, M., ScotT, C.T. and ZINGG, A., (1995): Evaluation of permanent sample surveys for growth and yield studies: a Swiss example. For. Ecol. Manage. 71:187-194

Loetsch, F., Zohrer, F. and Haller, K.E., (1973) : Forest inventory Vol. 2. Forest Inventory Section, Federal Research Organization for Forestry and Forest Products, Reinbek. BLV Verlagsgesellschaft mbh, Munchen, Germany, 469pp

Nakajima, N.Y., Yoshida, S. and Imanaga, M., (1995): Comparison among four ground-survey methods as a continuous forest inventory system for forest management. Jpn. For. Soc. 77:573-580

Nakajima, N.Y., Yoshida, S. and ImanaGa, M., (1996): Comparison of the accuracies of four ground-survey methods used for estimating forest stand values on two occasions. J. For. Plann. 2, (in press)

Pellico-netto, S. and Brena, D.A., (1993): Forest inventory. Federal University of Parana, Federal University of Santa Maria, Curitiba, PR, Brazil, 248pp (in Portuguese)

Schmid-haAs, P., Baumann, E. and Werner, J., (1993): Forest inventories by unmarked permanent sample plots: instructions. Swiss Federal Institute for Forest, Snow and Landscape Research. 136pp ScotT, C.T. and KoHL, M., (1994): Sampling with partial replacement and stratification. For. Sci. 40:30-46

Vanclay, J.K., Skovsgaard, J.P. and Hansen, C.P., (1995): Assessing the quality of permanent sample plot databases for growth modelling in forest plantations. For. Ecol. Manage. 71:177-186

WEST, P.W., (1995): Application of regression analysis to inventory data with measurements on successive occasions. For. Ecol. Manage. 71:227-234

YANG, Y.C. and WANG, C.H., (1987): Expectations and variances of basal area estimates using remeasured horizontal line sampling. For. Sci. 33:174-184

Yosuide, S., (1984): The application of the topographical classification to forest management. In IUFRO Symposium, Tokyo, Japan, 206-213

(Received 27 May 1996)

(Accepted 28 October 1996) 